\title{
Processos de construção do saber histórico escolar
}

Katia Maria Abud*

\section{RESUM0}

Este trabalho coloca em discussão o debate entre alguns conceitos que vêm sendo utilizados em documentos sobre ensino de história, particularmente os conceitos de saber histórico e conhecimento histórico. Discutir esses conceitos exige também que se retome o significado da escola e do ensino de história, face à crise da educação escolar e do próprio ensino de história.

Palavras-chave: saber histórico, conhecimento histórico, ensino de história.

Algumas afirmações são recorrentes quando se coloca em discussão 0 ensino de História e a formação de professores da disciplina para a escola básica. Documentos emitidos por historiadores ressaltam, por exemplo, a indissolubilidade dos laços entre o ensino e a pesquisa nos cursos de formação do professor de História. A pesquisa a que se referem, contudo, é a pesquisa acadêmica, que produz o conhecimento histórico, acadêmico, que pode ser destituído de qualquer relação com os objetivos do ensino de História. Por outro lado, a História a ser ensinada ou a que é apreendida pelos alunos não é considerada como um possível objeto de pesquisa. Subentende-se que a História como disciplina escolar prescinda de qualquer construção específica, pois é a divulgação e a difusão, em linguagem apropriada à faixa etária dos alunos, do conhecimento produzido nas universidades e outras instituições de pesquisa. Daí decorre que a produção de currículo não passa de listagem de conteúdos, listagem esta produzida seguindo parâmetros desta ou daquela Metodologia da História, que permita, contudo, que certas permanências se

* Professora de Metodologia do Ensino de História da Faculdade de Educação da Universidade de São Paulo. 
evidenciem. Uma dessas permanências sem dúvida é a periodização clássica, que depois de duas décadas de introdução dos eixos temáticos, vem presentemente retomando com muita força a tradição curricular.

Pesquisas vêm mostrando distorções na formação histórica dos alunos. Conceitos históricos, como o de revolução, não expressam, em alunos do terceiro ano do ensino médio de escola pública, avanços de aprendizagem, mas denotam a permanência do senso comum e apontam importância maior das representações sociais que se constroem independentemente do ambiente escolar (ALVES, 2005). Em outra pesquisa, em $5^{\text {a }}$ série de escola municipal de São Paulo, alunos afirmaram que a construção da História se faz por meio de vestígios, deixados pelas sociedades do passado. 0 historiador volta ao passado, segundo alguns alunos, utilizando uma máquina do tempo, segundo outros atravessando um portal e nessa "viagem" recupera os vestígios com os quais escreverá seus livros. Um aluno afirmou que os homens das cavernas eram historiadores, que voltaram ao passado e não conseguiram voltar (RIBEIRO, 2005). Parece claro que os meios de comunicação, como a televisão e o cinema deram uma importante contribuição para que os alunos elaborassem suas concepções de História e de tempo histórico.

Os professores das turmas pesquisadas são o que podemos chamar de bons professores: formados por cursos superiores em universidades nas quais 0 binômio ensino-pesquisa é valorizado, são interessados, permitiram 0 desenvolvimento da pesquisa em suas aulas com muita boa-vontade, demonstram domínio do conteúdo, usam técnicas e recursos didáticos, como fotos, filmes e vídeos. Mantém um relacionamento cordial com os alunos que se mantém relativamente atentos durantes as aulas.

0 conhecimento histórico escolar não pode ficar preso a análise de processos puramente cognitivos, independentes da vivência dos alunos, que lhes dá sustentação: o cognitivo é sempre sócio-cognitivo (LANTIER, 1994). Os alunos tendem a elaborar conceitos de acordo com sua experiência vivida e não formalizam o conhecimento histórico, se não tiverem a possibilidade de vivenciar movimentos e conceitos históricos, colocados em questão na sala de aula. Os indícios fornecidos pelos textos históricos, sejam eles o texto expresso pelo professor ou do manual didático, se concretizam no momento em que outros elementos da aprendizagem entram em jogo, como analogia e a empatia.

Para se apropriar de conceitos e noções presentes nos programas e 
planejamentos escolares, os alunos procedem segundo uma categorização, organizada a partir do acontecimento mais próximo ou mais familiar. Lantier (1994) afirma que a partir de um protótipo, uma espécie de nível básico para uma compreensão mais sólida, as noções suscetíveis de enriquecer tal nível de conceitualização por processos figurativos e, sobretudo por analogias. Para compreender o papel do exército nas ditaduras da América do Sul, por exemplo, os alunos recorrem ao nazismo e ao fascismo, ou para compreender a sociedade do Antigo Regime, elaboram uma grade social simplificada, nobres (ricos) e camponeses (pobres), muito semelhante à que lhes foi apresentada ao estudar a Idade Média. Uma boa escolha para situar socialmente os nobres e os camponeses, mas a mesma grade peca por omitir a burguesia.

Os mesmos processos analógicos se notam na relação entre fatos do passado e do presente e não somente em relação a dois fatos do passado, próximo ou distante. Para abordar os temas propostos os alunos utilizam-se de representações construídas na e fora da escola. Na medida em que os conceitos históricos são compreendidos pela sua relação com a realidade que o sujeito vivencia, ao procurar explicações para uma situação do passado à luz de sua própria experiência, mesmo sem apreciar as diferenças entre as suas crenças e valores e as de outra sociedade, revela já um esforço de compreensão histórica (BARCA e GAGO, 2001). Tal esforço de compreensão se revela a partir das tentativas de analisar as fontes históricas, o que constitui um elemento fundamental na progressão do conhecimento histórico. Contudo, os alunos dão sentido aos materiais históricos ao utilizar elementos fornecidos por sua vivência atual, num movimento oscilante, no qual algumas vezes modos de pensar simplistas podem se alternar com explicações mais elaboradas (LEE, apud BARCA e GAG0, 2001).

Aliado da analogia para a o desenvolvimento da compreensão histórica, o conceito de empatia facilita a compreensão histórica, ao aproximar as pessoas do passado às do presente. Há idéias e práticas do passado que oferecem explicações pouco satisfatórias se não forem analisadas na perspectiva da cultura, do sistema de valores e até o senso comum, num contexto material mais amplo, com o qual estão relacionados. 0 estudo do passado, utilizando as fontes nas aulas de História deve ser ancorado e contextualizado numa situação que faça sentido humano, obtido com a sua vivência e a experiência de 
aprendizado dentro e fora da escola. A compreensão histórica vem da forma como sabemos como é que as pessoas viram as coisas, sabendo o que tentaram fazer, sabendo o que sentiram em uma determinada situação.

A História como disciplina escolar não serve para "transformar os alunos em mini historiadores profissionais, como ironicamente questionou Peter Lee, mas

pode começar a ajudá-los a perceber como as interpretações históricas são baseadas na evidência, que as explicações não são o mesmo que afirmações factuais singulares, e que está na natureza da História haver diversas versões do passado, embora nada disto signifique que a História é apenas uma questão de opinião (LEE, 2001).

A formação histórica revela e define fundamentalmente os procedimentos da consciência histórica ou conhecimento histórico dando algumas indicações básicas sobre se dá essa formação:em todos os processos de aprendizagem que tem a história como objeto e que não se destinam, em primeiro lugar, à obtenção de competência profissional. Trata-se de um campo a que pertencem inúmeros fenômenos do aprendizado histórico: o ensino de História nas escolas, a influência dos meios de comunicação de massa e os fatores da vida humana prática (família, instituições e colegas), entre outros. Nesse campo se encontram, além dos processos de aprendizagem da ciência histórica, todos os demais que servem à orientação da vida pratica mediante a consciência histórica (RÜSEN, 2001). 0 conhecimento histórico é a principal ferramenta na construção dessa consciência histórica, que articula o passado com as orientações do presente e com as determinações do sentido com as quais o agir humano organiza suas intençoes e expectativas no fluxo do tempo. Mas, é nas escolas que se estuda a História e onde se cruzam de modo comprometido o conhecimento científico e o conhecimento escolar, por que o ambiente escolar é privilegiado para que os alunos aprendam maneiras de pensar sobre o passado que deverão ajudá-los a se orientar no tempo, relacionando o passado, o presente e o futuro com suas vivências como seres temporais. As representações históricas que os alunos constroem emergem de determinados processos da vida humana prática, que interagem com o conhecimento escolar.

Ao analisar as relações entre a História acadêmica e a História ensinada 
nas escolas, Moniot (2001) questiona não somente a ambigüidade do termo, como também a dupla face da História: de um lado, ela é construída pelo ensino, no sentido mais amplo do termo e por outro ela emerge da linguagem. social. Ao enfatizar a ambigüidade, esse autor reforça as contradições que cruzam a função educativa da História e os jogos sociais e políticos dos quais ela é objeto. Ele não considera a História como uma disciplina já "instalada" na escola, pois mesmo que exista como "História oficial", centralizada nas opções e conjunturas que constituíram a formação da nacionalidade, ela é, ao mesmo tempo, elaborada no meio social e por isso recebe uma tradução, na qual é condicionada por posições sociais e políticas. Sublinhar a ambivalência constitutiva de suas referências exige uma reflexão de natureza epistemológica sobre seus saberes e uma responsabilidade didática sobre sua transmissão. Encurralada entre um "distanciamento crítico" e "inculcação social", o campo do conhecimento histórico é atravessado por desafios: a erosão manifesta da noção de História que exige um olhar distanciado para reabilitá-la; sua inserção social, que se situa em diferentes níveis (nacional, mundial e intercultural); a confrontação com outras disciplinas (como as outras Ciências Sociais, o Direito), que interroga sua capacidade de pensar o possível.

Considerando-se que os conteúdos programáticos são feitos no dizer de Moniot (2001), sob a sombra protetora da ciência acadêmica, que sem dúvida é sua referência mais visível, desconhecem-se outras referências mais sutis da disciplina escolar: a prática e a cultura escolar, as representações sociais, 0 material didático. Desconsideram-se, sobretudo, as relações entre a História e a vida prática, ou em outras palavras, para que serve a História ensinada nas escolas, que diferentemente da sua matriz acadêmica, tem como público aquele que não é necessariamente, um pesquisador, um historiador.

A instituição escolar possui certa autonomia em relação à demanda social que legitima sua função. Os professores elaboram seus instrumentos de trabalho, suas modalidades de intervenção, suas práticas profissionais que constituem uma cultura própria da escola. A aceitação da existência de uma cultura própria da escola levou a aprofundamentos a respeito do ensino das disciplinas escolares e a formas pelas quais se apresentavam, originando a discussão sobre a transposição didática, isto é, a origem e a transformação do saber para que ele seja ensinado (MARTINAND, 2001, p. 17-23). As interações 
entre o saber acadêmico, cultura escolar e outros elementos componentes das representações sociais dos alunos e professores constituem a base sobre a qual se assenta o saber escolar. No interior de cada disciplina escolar, as pesquisas didáticas integram a reflexão epistemológica, para definir os conhecimentos relativos aos procedimentos e noções a serem desenvolvidas pelos alunos para que cheguem a um nível de conhecimento, às articulações entre conhecimentos procedimentais e competências nocionais para a resolução de determinadas tarefas em uma mesma disciplina ou em várias delas (DEVELAY, 1993, p. 59).

Ao trazer as questões para nossas aulas de História e a organização curricular da História diferentes questões se colocam, pois se evidenciam a força do conhecimento acadêmico e as frágeis relações entre os currículos e programas, a cultura escolar e a vivência dos sujeitos escolares. Primeiramente, somos portadores de uma tradição que nos mantém como continuidade da civilização ocidental, que se iniciou no Oriente Médio, quando os homens inventaram a escrita. Acreditamos que, por isso, não podemos escapar de um ensino que não se organize pela cronologia e pela predominância da periodização clássica. A exclusão de Estudos Sociais e a reintegração de História e Geografia como disciplinas escolares geraram novas propostas curriculares, nos anos 1980.

0 surgimento de uma produção histórica que se pautava por críticas às formas então consideradas tradicionais e pela introdução de conceitos e categorias explicativas que até então eram desconsideradas forneceram 0 embasamento necessário para que os novos currículos e propostas se orientassem pela negação ao etnocentrismo, pela valorização do cotidiano como categoria explicativa e pela rejeição ao quadripartismo da História. A reorganização da História a ser ensinada, pelo menos nos documentos curriculares oficiais, passou a ser regulada por outros parâmetros e a se fundamentar em conceitos e categorias explicativas, que até então não tinham sido consideradas para 0 conhecimento escolar, como o cotidiano. Surgiram também diferentes propostas de periodização que fugiam da divisão quadripartite da História e sugeriam a tematização do currículo como um modo de superar a organização cronológica, que se fixava quase sempre na datação.

Os Parâmetros Curriculares Nacionais, elaborados na segunda metade da década de 90, partilhavam algumas das sugestões dos documentos anteriores, especialmente no que dizia respeito à organização dos conteúdos conceituais 
por meio de eixos temáticos. Contudo, dentro dos eixos a cronologia era retomada, numa listagem seqüencial de acontecimentos, conforme se pode observar com facilidade na leitura dos conteúdos conceituais sugeridos para 0 quarto ciclo (Parâmetros Curriculares Nacionais, 1998).

A penetração nas escolas dos documentos curriculares tem como veiculo preferencial os manuais didáticos, que os manipulam para atender os objetivos de sua produção. Dessa forma, os eixos temáticos desapareceram, com raras exceções. A maioria das coleções didáticas se organiza atualmente dispondo os conteúdos numa ordenação cronológica, alternando capítulos da História Geral e do Brasil, incluindo alguns temas de História da América. Como o eixo organizador é a passagem do tempo, nem sempre há continuidade temática nos volumes das coleções.

Mas, a ênfase deve ser dada num aspecto que limita a aprendizagem com a finalidade de construção da consciência histórica do aluno: o predomínio dos temas da História Geral sobre a História do Brasil (e da América) e com ele o a utilização de recursos, como ilustrações, textos historiográficos e documentais complementares. Os quatro volumes dos manuais didáticos destinados ao segundo nível do ensino fundamental têm três quartos de suas páginas ocupadas pela Historia Geral e um pequeno espaço para a Historia do Brasil. Assim se distribuem os conteúdos nas coleções: o primeiro volume destinado à quinta série é inteiramente destinado ao estudo da Pré História e História Antiga, excepcionalmente algumas coleções abrem espaço para os índios do Brasil, no período pré-histórico e para sociedades indígenas do México e dos Andes, introduzidos no espaço destinado à Antigüidade. 0 volume destinado à sexta série dedica metade do seu espaço ao período medieval, concentrando-se na Europa, com algumas páginas para o Império Árabe e para Bizâncio. Desenvolvem-se ainda os temas próprios da transição, como Renascimento, Reforma, Absolutismo para se chegar enfim ao período das navegações portuguesas e finalmente, os europeus desembarcam nas costas que hoje são brasileiras. A partir daí, somente depois da chegada dos europeus é que se inicia para nossos estudantes, a História do Brasil. Aquilo que os livros didáticos chamam de "História integrada" não passa, enfim, de uma frágil articulação entre a História Geral e a do Brasil, mera sobreposição cronológica dos conteúdos.

Não se trata apenas de um problema relativo à quantidade dos conteúdos, 
mas também perdem espaços temas fundamentais para a compreensão da sociedade brasileira e da nossa identidade enquanto parte dela. Muitas vezes, temas fundamentais são estudados sub-títulos de capítulos. Boa parte das coleções inclui, por exemplo, a escravidão como sub-item de um capítulo maior sobre a instalação dos engenhos. 0 tema é retomado rapidamente, também incluído como sub-item, no capítulo sobre os anos finais do Império. De modo geral, trezentos anos da História do Brasil são estudados sem que a escravidão seja retomada.

Diga-se, a bem da verdade que as abordagens muitas vezes correspondem ás novas tendências historiográficas, com a inclusão de sujeitos até recentemente desconsiderados pelo saber histórico escolar, como mulheres, crianças, trabalhadores. Mas, o pano do fundo permanece na construção das representações dos alunos: a nossa história é uma continuação da européia. Os modelos de análise são modelos elaborados para a análise da sociedade européia, não da sociedade brasileira (Programa Nacional do Livro Didático 2002, 2001).

Se

o conhecimentos histórico só é assimilado pelos alunos quando estes compreendem que os vestígios do passado como evidência no seu mais profundo sentido, ou seja, como algo que deve ser tratado não como mera informação, mas como algo de onde se possam retirar respostas a questões que nunca se pensou colocar (DUARTE, 2005).

nosso aluno não terá no ensino de História nas escolas o alicerce para a construção da consciência histórica. Essa construção que se apóia nas representações sociais dos alunos terá dificuldade em se concretizar pois, as representações sociais não se constituem em discursos neutros e por isso, favorecem a relação com o mundo, na construção, por meio de múltiplos discursos, da realidade social. Visam o reconhecimento de uma identidade social, pela qual marcam de forma visível a existência do grupo, da classe ou da comunidade. Cabe à interação entre as duas formas de conhecimento histórico: o acadêmico e o escolar auxiliar o aluno na transformação das representações sociais e na formação histórica para a construção da consciência histórica. 


\section{Referências}

ALVES, R. C. O confronto de representações sociais como possibilidade de construção de consciência bistórica. Relatório Geral de Qualificação, nível mestrado. São Paulo: FEUSP, 2005 (texto digitalizado).

BARCA, I.; GAGO, M. A prender a pensar em História: um estudo com alunos do $6^{\circ}$ ano de escolaridade. Revista Portuguesa de Educação, 2001, 14(1), p. 239-261.

DEVELAY, M. De l'apprentissage a l'enseignement. Pour une épistémologie scolaire. Paris: ESF, 1993, p. 59.

DUARTE, M. J. F. Representações dos movimentos político-culturais da década de 60 nos jovens do ensino médio. Dissertação de mestrado apresentada á Faculdade de Educação da Universidade de São Paulo, 2005.

LANTIER, N. L histoire approprié par les élèves. Psychologie cognitive et didactique de I histoire. In: MONIOT, H. et SERWANSKI, M. (dir.). L'bistoire en partage 1: le récit de vrai. Paris: Nathan pédagogie, 1994, p. 45-55.

LEE, P. Progression in children's history. Tsing Hua Newsletter for teaching bistory, 3, 1994: p. 5-3, apud BARCA, Isabel e Gago, M. op. cit.

LEE, P. Prefácio. In: BARCA, I. O pensamento bistórico dos jovens. Braga: CEEP/ Universidade do Minho, 2000.

MONIOT, H. La question de la référence en didactique de lhistoire. In : TERRISSE, A.. Les références au savoir. Bruxelles : Éditions De Boeck Université, 2001: p. 65-76.

MARTINAND, J.-L. Pratiques de référence et problematique de la référence curriculaire. In: TERRISE, A. (Éd.) Didactique des disciplines. Les références au savoir. Bruxelles: Éditions De Boeck Université, 2001: p.17-23.

PROGRAMA NACIONAL DO LIVRO DIDÁTICO, 2002. Guia dos livros didáticos. $5^{a}$ a $8^{a}$ séries. Brasília: Ministério da Educação, 2001.

RIBEIRO, R. M. de 0. Relatório de Pesquisa, São Paulo: FEUSP, $1^{\circ}$ sem. de 2005 (texto digitalizado).

RÜSEN, J. Razão bistórica. Teoria da bistória: os fundamentos da ciência bistórica. Trad. Estevão de Rezende Martins. Brasília: Editora UnB, 2001: p. 51. 


\section{Processes of construction of schoolchild historic known}

\section{ABSTRACT}

This text presents a discussion about the debate among some concepts that have been used in documents about History Teaching, especially the concepts of the historical knowledge and the historical understanding. It's necessary to recover the meaning of School and History Teaching to discuss these concepts because of the actual crisis of Historical Education and History teaching.

Key-words: historical knowledge, historical understanding, history teaching. 